\title{
Prevalence of Selfitis among Nursing Personnel in Ranchi
}

\author{
Farzana Begum* \\ College of Nursing, Rajendra Institute of Medical Sciences, Ranchi, Jharkhand, INDIA.
}

Received: 03 Aug 2019;

Accepted: 01 Oct 2019

*Correspondence to:

Dr. Farzana Begum,

Assistant Professor, College of Nursing, Rajendra Institute of Medical Sciences, Ranchi, Jharkhand, INDIA. Email:farzana.skgm@gmail.com Copyright: (c) the author(s),publisher and licensee Indian Academy of Pharmacists. This is an open-access article distributed under the terms of the Creative Commons Attribution Non-Commercial License, which permits unrestricted non-commercial use, distribution, and reproduction in any medium, provided the original work is properly cited.

\begin{abstract}
Background: Advent of social networking has changed the entire communication system. People have become more expressive and opinionated. It is also used to fulfil individuals' identity need, typically, those suffer from a lack of self-confidence and are seeking to 'fit in' with those around them. ${ }^{[1]}$ Therefore some people take selfies and continually posts them on social media to get online appreciation in the form of 'likes' and 'comments'. Psychologists have warned that 'selfitis' is an ailment that needs attention and people who suffer from this need help. Objectives: To explore the prevalence of selfitis among nursing personnel and their purpose of taking selfie. Methods: : This is a cross sectional analysis of data collected from 444 nursing personnel from selected hospitals of Ranchi city with the help of selfitis behaviour scale. Data were evaluated through frequency and percentage. Results: Sixty-nine percent nursing personnel suffering from acute selfitis, whereas $21 \%$ chronic and $10 \%$ borderline. Among them $67 \%$ like to take selfies sometimes, $26 \%$ rarely and $7 \%$ regularly take selfies. Conclusion: Though selfitis is not yet recognised as a problem officially, not included in DSM - 5 yet, but any obsession is a real problem and leads to negative impact, therefore efforts should be taken to increase awareness and prevent such issue.
\end{abstract}

Key words: Prevalence, Selfitis, Nursing, Students, Ranchi.

\section{INTRODUCTION}

No one can deny that the selfie culture is quite popular nowadays. Taking selfie and uploading them on social media to get more likes and comments has taken a new dimension called 'selfitis'. The term "Selfitis" was first coined in 2014 by American psychiatric Association as a mental disorder. American Psychiatric Association defined selfitis as an obsessive compulsive desire to take photos of self to look good and to post on social media. ${ }^{[2]}$ Why this is happening may need some more studies to explore the underline causes but it can be Attention Seeking Syndrome (ASS). Easy access to technology has given a means to the tendency for expression of ego or esteem needs of the human beings as given in Maslow's Need-Hierarchy Theory. ${ }^{[3]}$ Though the behavior officially not described as a problem yet, certain behavior can be addictive in the sense if one continue to do them again and again and have harmful consequences and if someone is involved in such behavior, can still get help from a treatment professional no matter what it is. More focus should be given on risk factors because if focus only given to treatment, at the point someone needs treatment, significant damage may have already done. The present study was conducted to identify the prevalence of selfitis and purpose of taking selfies among nursing personnel from selected hospitals in Ranchi.

\section{METHODS}

The present study used a qualitative approach and an exploratory survey design to identify the prevalence of selfitis among nursing personnel age ranged between 25 to 45 years with average age of 24.385 years who were working in various hospitals in Ranchi city, Jharkhand. The study conducted in the year 2019, screening done through the Selfitis Behavior Scale (SBS). ${ }^{[4,5]}$

Prior permission taken from the owner of the tool for the implementation in the study. The SBS scale is a 20 item likert scale. The answers can be rated as $1=$ strongly disagree, $2=$ disagree, $3=$ not sure, $4=$ agree and $5=$ strongly agree.
The sum total of the answers of all the 20 questions will determine the level of selfitis as 0-33 borderline, 34-67 acute and 68-100 chronic. Data collected from 444 nursing personnel. All the nursing personnel were explained about the purpose of the study and assured for confidentiality. They gave their consent for participation in the study. All the subjects were asked to fill the questionnaires in the presence of the researchers. Data collected and analysed by frequency percentage to find out the prevalence of selfitis.

\section{RESULTS}

N. B. - The SBS is a five point like scale consisting of two negative response (strongly disagree and disagree), one neutral response (not sure) and two positive response (agree and strongly agree). In Table 2. Only the sum total of frequency and percentage of positive response taken into consideration for discussion and the items of the SBS arranged in a descending order as per the findings. Table 1 showing out of 444 nursing personnel, 94 having chronic, $69 \%$ acute and $10 \%$ borderline selfitis.

Table 2 showing that the five most common purpose of taking selfie among nursing personnel are, taking selfie provides better memories about the occasion (910\%), taking selfies as trophies for future memories $(8 \%)$, taking selfie gives a good feeling to enjoy environment ( $8 \%$ ), taking selfie improves mood and makes feel happy $(7 \%)$ and using photo editing tools to look better than others $(6 \%)$. Whereas the five least common purpose of taking selfie are, to gain enormous attention, more acceptance among peer group, feel more popular, become a strong member of peer group, feel detached from peer group and each of the purpose scored 3\%. Figure 1 Shows $21 \%$ nursing personnel having chronic, $69 \%$ acute and 10\% borderline selfitis. Figure 2 Shows 7\% nursing personnel taking selfies regularly, 67\% sometimes and $26 \%$ rarely taking selfies. Figure 3 Shows purpose of selfie taking among the nursing personnel. 
Begum.: Prevalence of Selfitis among Nursing Personnel in Ranchi

Table 1: Prevalence of various levels of selfitis among nursing personnel.

\begin{tabular}{|l|l|l|l|}
\hline Level of selfitis & SBS Score & $\begin{array}{l}\text { Frequency } \\
\mathbf{N = 4 4 4}\end{array}$ & $\begin{array}{l}\text { Percentage } \\
\%\end{array}$ \\
\hline Borderline & $0-33$ & 46 & 10 \\
\hline Acute & $34-67$ & 304 & 69 \\
\hline Chronic & $68-100$ & 94 & 21 \\
\hline
\end{tabular}

Table 1 showing $21 \%$ nursing personnel having chronic, $69 \%$ acute and $10 \%$ borderline selfitis..

\section{various levels of selfitis among nursing personnel}

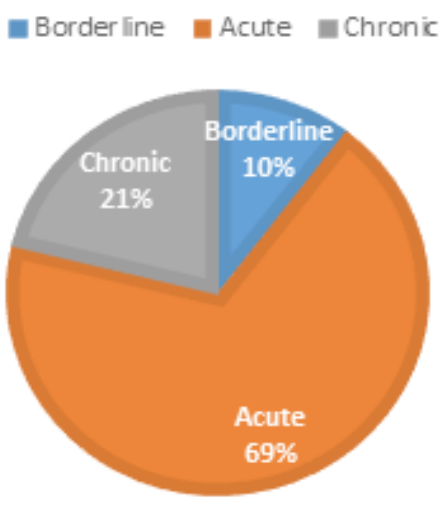

Figure 1: Shows $21 \%$ nursing personnel having chronic, $69 \%$ acute and $10 \%$ borderline selfitis.

\section{FREQUENCY OF TAKING SELFIE AMONG NURSING PERSONNEL}

- Regularly nometime arely

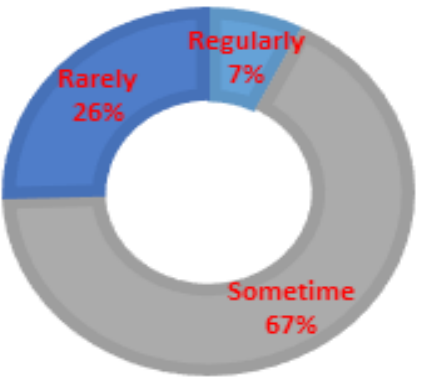

Figure 2: Shows 7\% nursing personnel taking selfies regularly, $67 \%$ sometimes and $26 \%$ rarely taking selfies.

\section{DISCUSSION}

The present study is an attempt to explore the selfitis behaviour among nursing personnel. Four hundred and forty-four nursing personnel participated in the survey. There was very limited number of studies conducted in this regard.
Table 2: Purpose of selfie taking among the nursing personnel.

\begin{tabular}{|c|c|c|}
\hline Purpose of selfie taking & $n$ & $\%$ \\
\hline Provides better memories about the occasion & 320 & 10 \\
\hline Take selfies as trophies for future memories & 254 & 8 \\
\hline Gives a good feeling to enjoy environment & 236 & 8 \\
\hline Improves mood and makes feel happy & 202 & 7 \\
\hline Use photo editing tools to look better than others & 178 & 6 \\
\hline Become more positive about self & 171 & 6 \\
\hline Expect friends to appraise & 157 & 5 \\
\hline Instantly modifies mood & 156 & 5 \\
\hline Feel confident when take a selfie & 154 & 5 \\
\hline To increase confidence & 143 & 5 \\
\hline Able to reduce stress & 136 & 4 \\
\hline Able to express more & 132 & 4 \\
\hline Helps increase social status & 121 & 4 \\
\hline 'Likes' and comments & 118 & 4 \\
\hline Creates healthy competition with friends & 112 & 4 \\
\hline Gain enormous attention & 105 & 3 \\
\hline Gain more acceptance among peer group & 101 & 3 \\
\hline Feel more popular & 92 & 3 \\
\hline Become a strong member of peer group & 90 & 3 \\
\hline When don't take selfies, feel detached from peer group & 78 & 3 \\
\hline
\end{tabular}

\section{SELFIE TAKING PURPOSE AMONG NURSING PERSONNEL}

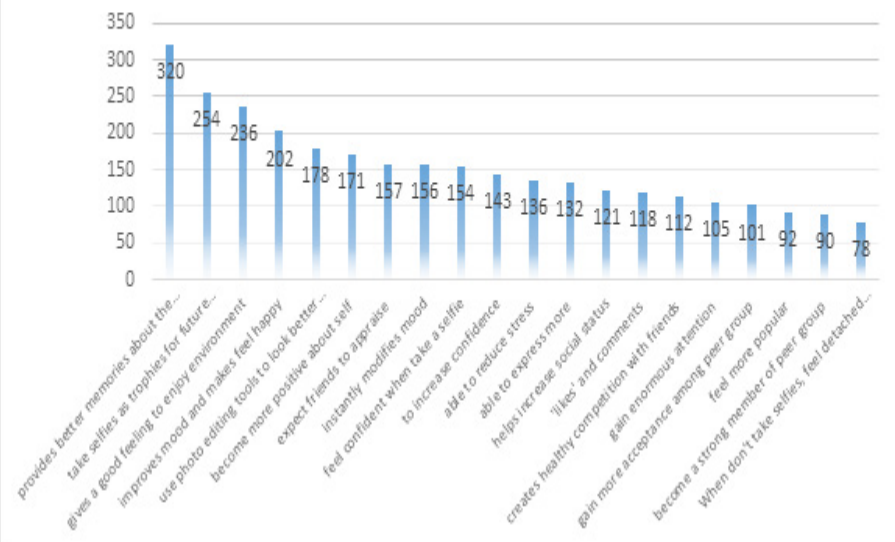

Figure 3: Shows purpose of selfie taking among the nursing personnel.

The findings (Table 1) of the present study revealed $21 \%$ nursing personnel having chronic, $69 \%$ acute and 10\% borderline selfitis. The finding is supported by the study conducted by Singh et al. ${ }^{[6]}$ which found majority of $(70.5 \%)$ nursing students had moderate selfitis followed by $(29.50 \%)$ 


\section{Begum.: Prevalence of Selfitis among Nursing Personnel in Ranchi}

severe selfitis.

Seven percent nursing personnel taking selfies regularly, 67\% sometimes and $26 \%$ rarely taking selfies (Figure 1) which is in contrast to the findings of the study conducted by Veena. G and M. Krishnamurthy ${ }^{[7]}$ that reported $65 \%$ of respondents take selfies regularly $20 \%$ sometimes, $10.83 \%$ rarely and $4.17 \%$ of respondents never take selfies.

The five most common purpose of taking selfie among nursing personnel (Table 2) are, taking selfie provides better memories about the occasion (9$10 \%)$, taking selfies as trophies for future memories $(8 \%)$, taking selfie gives a good feeling to enjoy environment $(8 \%)$, taking selfie improves mood and makes feel happy $(7 \%)$ and using photo editing tools to look better than others $(6 \%)$. Whereas the five least common purpose of taking selfie are, to gain enormous attention, more acceptance among peer group, feel more popular, become a strong member of peer group, feel detached from peer group and each of the purpose scored 3\%. Similar result were also found in the study conducted by Janarthanan Balakrishnan and Mark D. Griffiths, ${ }^{\left[{ }^{[]}\right.}$ Singh V. and Yadav A. ${ }^{[6]}$ and Veena.G and M.Krishnamurthy. ${ }^{[7]}$

Like any of the study this study also has its limitations. All the data were self-report and are subject to many well-known biases like social desirability and memory recall. The sample was a convenience sample therefore is a non-representative of other populations and cultures.

The vast majority of the sample $(90 \%)$ was below the age of 40 years; therefore, further research should attempt to examine the selfitis across different age groups and populations using more representative samples.

\section{CONCLUSION}

The present study has proved that selfie syndrome is dominantly developing craze of modern era due to increased digitalization, easy access to internet and inexpensive gadgets with internet access. From the present study it is concluded that the majority of nursing personnel have acute selfitis. Therefore, if awareness increasing measures not taken then this majority group may become chronic and the present study is helpful to develop awareness and provide a baseline information.

\section{CONFLICT OF INTEREST}

The author declare that there are no conflicts of interest.

\section{REFERENCES}

1. Knapton Sarah. Selfitis' - the obsessive need to post selfies - is a genuine mental disorder, say psychologists available at https://www.telegraph.co.uk/ science/2017/12/15/selfitis-obsessive-need-post-selfies-genuine-mental-disorder/ accessed on 30/07/2019

2. Darakshan Zia. "Selfitis": Know the Disease. Available at https://www. greaterkashmir.com/news/opinion/selfitis-know-the-disease/ accessed on 30/07/2019

3. Pathak Pramod. Etiology of selfitis available at https://www.dailypioneer.com/2018/ columnists/etiology-of-selfitis.html accessed on 30/07/2019

4. Balakrishnan J. Griffiths MD. Int J Ment Health Addiction (2018) 16: 722. Available at https://doi.org/10.1007/s11469-017-9844-x accessed on 30/07/2019

5. https://www.healthline.com/health-news/do-you-know-somebody-who-suffersfrom-selfitis\#1 accessed on accessed on 30/07/2019

6. Singh V, Yadav A. A study to assess the selfitis behaviour and selfie syndrome (level of selfitis) among the nursing students. Int J Med Res Rev 2018;6(08):452457. doi:10.17511/ijmrr.2018.i08.09.

7. Veena g. Perception Towards Capturing Selfies And Its Impact Among Students Of Mangalore University: A Study. International Journal of Digital Library Services. Vol. 5, October - December 2015, Issue - 4 .

Cite this article as: Begum F. Prevalence of Selfitis among Nursing Personnel in Ranchi. J Pharm Pract Community Med. 2019;5(3):51-3. 